\title{
Sonidegib: mechanism of action, pharmacology, and clinical utility for advanced basal cell carcinomas
}

\author{
This article was published in the following Dove Press journal: \\ OncoTargets and Therapy \\ 16 March 2017 \\ Number of times this article has been viewed
}

\section{Sachin Jain' \\ Ruolan Song ${ }^{2}$ \\ Jingwu $\mathrm{Xie}^{2}$}

'Indiana University School of Medicine, ${ }^{2}$ Department of Pediatrics, Herman B Wells Center for Pediatric Research, Indianapolis, IN, USA
Correspondence: Jingwu Xie

Department of Pediatrics, Herman B Wells Center for Pediatric Research, 1044 W. Walnut St., Rm 327, Indianapolis, IN 46202, USA

Email via jinxie@iu.edu

\begin{abstract}
The Hedgehog (Hh) pathway is critical for cell differentiation, tissue polarity, and stem cell maintenance during embryonic development, but is silent in adult tissues under normal conditions. However, aberrant Hh signaling activation has been implicated in the development and promotion of certain types of cancer, including basal cell carcinoma (BCC), medulloblastoma, and gastrointestinal cancers. In 2015, the US Food and Drug Administration (FDA) approved sonidegib, a smoothened (SMO) antagonist, for treatment of advanced BCC (aBCC) after a successful Phase II clinical trial. Sonidegib, also named Odomzo, is the second Hh signaling inhibitor approved by the FDA to treat BCCs following approval of the first SMO antagonist vismodegib in 2012. What are the major features of sonidegib (mechanism of action; metabolic profiles, clinical efficacy, safety, and tolerability profiles)? Will the sonidegib experience help other clinical trials using Hh signaling inhibitors in the future? In this review, we will summarize current understanding of BCCs and Hh signaling. We will focus on sonidegib and its use in the clinic, and we will discuss ways to improve its clinical application in cancer therapeutics.
\end{abstract}

Keywords: Hedgehog, smoothened, inhibitor, cancer, basal cell carcinoma, sonidegib

\section{Introduction}

Since the discovery of the Hedgehog (Hh) gene in the fruit fly in 1980, significant progress has been made in our understanding of the role of its signaling pathway, not only in the regulation of cell differentiation during development, but also in the development of cancer. ${ }^{1}$ Three homologues of the Hh gene have been identified: Sonic hedgehog (Shh), Desert hedgehog (Dhh), and Indian hedgehog (Ihh). ${ }^{2-6}$ The Hh signaling pathway is highly conserved, including the ligands (Shh, Dhh, Ihh), patched receptors (PTCH1, PTCH2), signal transducer smoothened (SMO), and Gli transcription factors (Gli1, Gli2, Gli3). Without binding of Hh ligand to the transmembrane patched receptor, patched will inhibit the function of SMO. Binding of Hh ligand releases this inhibition, allowing SMO to signal downstream and activate the Gli transcription factors. Gli can bind to the promoter regions of their target genes, regulating their expression. ${ }^{7-9}$ Studies have revealed additional mechanisms controlling signaling of this pathway, such as the role of cilium in Hh signaling, ${ }^{10-12}$ co-receptors of Hh molecules, ${ }^{13-15}$ potential molecules mediating PTCH1-mediated SMO suppression, ${ }^{16}$ and ways for Gli transcription factor regulation. ${ }^{17-20}$ This pathway is referred to as canonical signaling. In addition, Gli transcription factors can be also activated in the noncanonical fashion by KRAS, TGF $\beta$, PI3K, and PKC (Figure 1). Any mutation in these pathways may lead to abnormal fetal development as well as malignant disease in adults. 

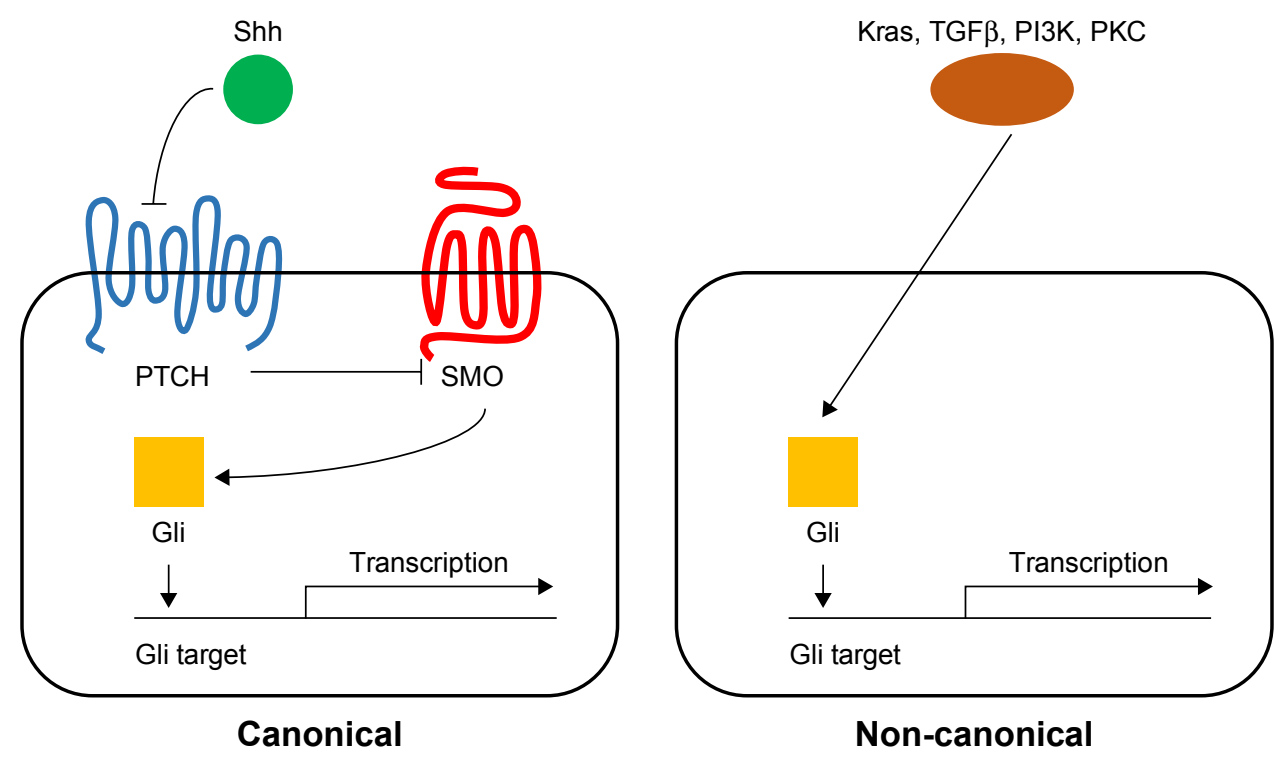

Figure I Canonical $\mathrm{Hh}$ signaling and noncanonical Hh signaling.

Abbreviations: Hh, Hedgehog; PTCH, patched; Shh, Sonic hedgehog; SMO, smoothened.

Since its connection to human cancer development, numerous compounds have been discovered to have inhibitory effects on Hh signaling. As of yet, two compounds (vismodegib and sonidegib) have been approved by the US Food and Drug Administration (FDA) to treat basal cell carcinomas (BCCs). In this review, we will focus on sonidegib: its discovery, mechanism of action, and clinical utility for advanced BCCs (aBCCs).

\section{The Hh pathway in cancer development}

The Hh signaling pathway was first linked to cancer development when it was found that mutations in PTCH1 are linked to a rare and hereditary form of $\mathrm{BCC}$, basal cell nevus syndrome (BCNS), also known as Gorlin syndrome. ${ }^{21,22}$ Gorlin syndrome has two major phenotypes: developmental defects and an increased risk of developing cancers that are associated with Hh signaling mutations, including BCC, medulloblastoma, rhabdomyosarcoma, and meningioma.

The majority of BCCs and other Gorlin syndrome associated cancers, including rhabdomyosarcomas, meningiomas, and medulloblastomas, have mutations in PTCH1, SMO, and other Hh pathway molecules or an elevation in Hh target gene expression. Based on these findings, it has been suggested that Hh signaling plays several roles in cancer development: as a tumor driver, tumor promoter, tumor metastasis promoter, or cancer stem cell promotor. As previously discussed, activating mutations of Hh signaling can drive the development of BCCs, medulloblastomas, rhabdomyosarcomas, gastrointestinal stromal-like tumors, and Barrett's esophagus. ${ }^{23}$ In small cell lung cancer (SCLC), Hh signaling can promote cancer development but cannot drive tumor formation. In pancreatic cancers, inhibiting Hh signaling can prevent tumor invasion and metastasis. Finally, Hh signaling can regulate cancer stem cell numbers as well as the tumor microenvironment, creating conditions that promote tumor growth. This role of $\mathrm{Hh}$ signaling can be found in leukemia and liver cancer, and is often responsible for the recurrence of cancer through resistance to chemotherapy and radiotherapy. ${ }^{24-33}$ Dysregulation of any component of the Hh pathway leading to its aberrant activation can result in malignant conditions through these mechanisms.

\section{BCC}

$\mathrm{BCC}$ is the most common form of skin cancer and among the most commonly diagnosed forms of cancer in the USA, with over one million cases per year. ${ }^{34}$ Although it has a low risk for metastasis, it is a slow growing tumor that causes morbidity via its proximity to critical facial structures. It also has a tendency to relapse, occur in multiple locations, and invade and destroy local tissues.

Classification of BCCs is dependent on prognostic factors including tumor size, histological characteristics, tumor location, margins, and recurrence. Usually, superficial BCC is treatable with nonsurgical techniques including photodynamic therapy and topical imiquimod or 5-fluorouracil treatment, or by surgical techniques including 
electrodessication, Mohs micrographic surgery, excisional surgery, cryosurgery, or laser surgery. However, invasion of the $\mathrm{BCC}$ into surrounding muscle, bone, or cartilage results in locally advanced BCC. Unfortunately, these tumors are incurable, or not treatable by surgery or radiotherapy. Successful treatment is dependent on tumor progression, a history of previous treatments, and any medical contraindications. Cytotoxic chemotherapy has not been approved for treatment of nonresectable BCC, and these patients can only benefit from palliative care. Metastatic BCC $(\mathrm{mBCC})$ is extremely rare, with an incidence of up to $0.55 \%$ of cases. It commonly affects the regional lymph nodes, lungs, and liver. The prognosis of $\mathrm{mBCC}$ is very poor, with a mean survival between 8 months and 3.6 years. Both locally advanced BCC (laBCC) and $\mathrm{mBCC}$ can be collectively referred to as aBCC. Unfortunately, treatment of aBCC was nonexistent until the recent development of Hedgehog pathway inhibitors (HPIs).

There are a number of small molecules targeting SMO, with potent activity to treat Hh-driven aBCC. Although several compounds are shown to target Gli transcription factors or the $\mathrm{Hh}$ molecules, their specificity and potency to treat aBCC have not been demonstrated in clinical trials. Currently, seven small molecule inhibitors are under clinical trial or have been approved to target SMO in the treatment of Hh-driven cancers. These SMO inhibitors include cyclopamine derivatives IPI-926 (saridegib), GDC0449 (vismodegib), BMS833923 (XL-139), PF04449913 (glasdegib), LY2940680 (taladegib), LEQ506, TAK-441, and LDE-225 (NVP-LDE225, sonidegib). ${ }^{8,35-37}$

\section{Discovery, modifications, and mechanism of action of sonidegib}

Sonidegib, marketed as Odomzo by Novartis, was approved by the FDA in July 2015 as a $200 \mathrm{mg}$ oral pill for treatment of

A

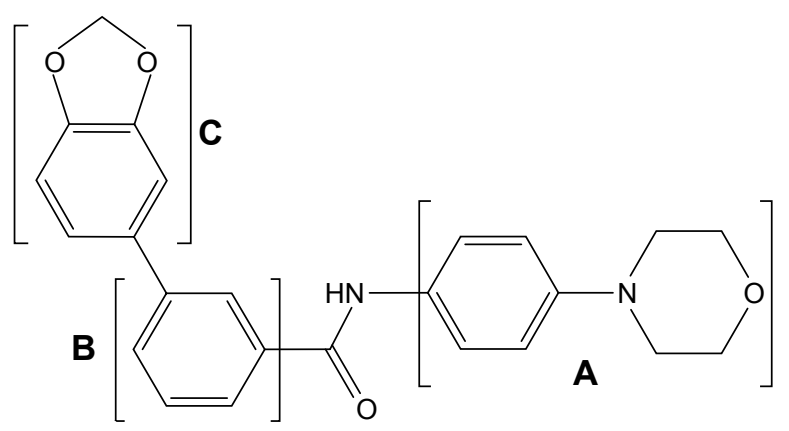

recurrent $\mathrm{aBCC}$, or $\mathrm{aBCC}$ in patients who are not eligible for surgery or radiation therapy. It is currently being investigated for use in the treatment of other cancer types.

Sonidegib belongs to a class of biphenyl carboxamides and was discovered as an SMO antagonist using a highthroughput screen in vitro. ${ }^{38}$ A structure-activity relationship study was performed using variations in three regions of the originally identified molecule, compound 1 , which is the core structure of sonidegib (Figure 2A). First, modification to region $\mathrm{A}$ with a nitrogen in the pyridine moiety and the addition of cis-dimethyl groups on the morpholine ring helped to mitigate the risk of widespread toxicity by reducing electron density. Next, the addition of a methyl group in region $\mathrm{B}$ increases the potency to inhibit SMO. Furthermore, a modification to region $\mathrm{C}$ with $-\mathrm{OCF}_{3}$ at the $\mathrm{R}_{4}$ position yielded $5 \mathrm{~m}$ (NVP-LDE225; Figure 2B), with the most favorable pharmaceutical properties, ADMET (absorption, distribution, metabolism, excretion, and toxicity) properties, and pharmacokinetics.

Sonidegib interacts with SMO in the drug-binding pocket, where it acts as an antagonist, preventing downstream activation of Hh pathway signaling (Figure 3). ${ }^{39-42}$ Based on the recently reported SMO structure, there are numerous residues in the drug-binding pocket interacting with a SMO antagonist. It was reported that residues from the extracellular tips of helices I, II, V, and VII interact with LY2940680. The most notable interaction is between R400 of helix V and the compound via the phthalazine ring. Several structured water molecules in the ligand pocket are also critical for the interactions, including R400, H470, D473, E518, and N521 side chains. Mutations within the pocket, including Q476 and D473, prevent sonidegib binding. Other mutations, including S533 and W535, cause conformational changes in SMO, blocking sonidegib from accessing the drug-binding

B

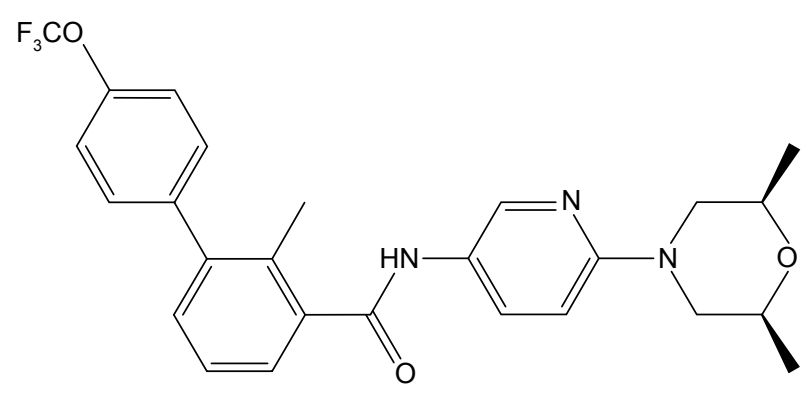

Figure 2 Generation of Sonidegib.

Notes: (A) The structure of compound \#I from a cell-based screening. (B) The structure of sonidegib, which has high biological potency. 


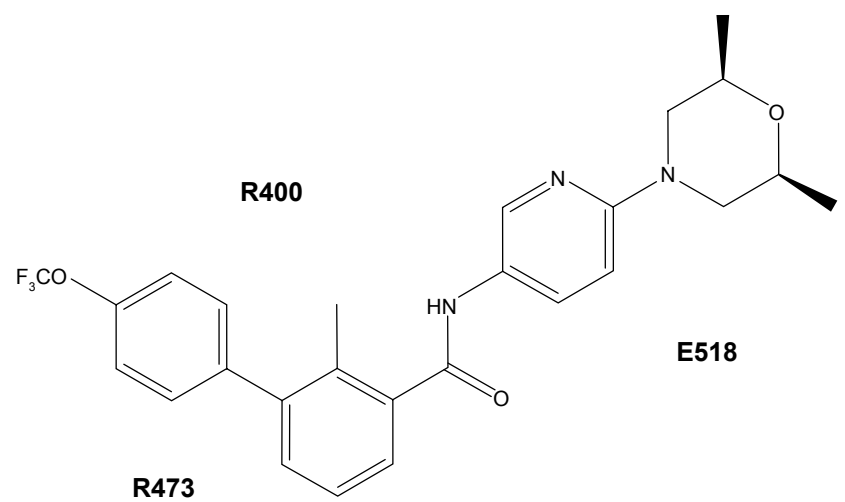

Figure 3 Sonidegib interacts with the drug-binding pocket of SMO, which mainly consists of three amino acids: arginine (R) 473 , arginine (R) 400 , and glutamic acid (E) 518 .

Abbreviation: SMO, smoothened.

pocket. ${ }^{42}$ These mutations have been found to confer resistance to sonidegib. ${ }^{43}$

\section{Metabolic profiles and pharmacokinetics of sonidegib}

Sonidegib has a unique metabolic profile. While the $\mathrm{T}_{\max }$ for sonidegib in blood and plasma is only $2-3 \mathrm{~h}$, the $\mathrm{T}_{\max }$ for its main metabolite M48 is $60 \mathrm{~h}$, suggesting that sonidegib is slowly metabolized by the body. The $T_{1 / 2}$ for sonidegib is over 14 days. ${ }^{44}$ Similarly, the $\mathrm{T}_{\max }$ for vismodegib is $\sim 2 \mathrm{~h}$ with $\mathrm{T}_{1 / 2}$ in the plasma around $7-14$ days. ${ }^{45,46}$ Vismodegib is also a slowly metabolized compound, with the major metabolite M1 appearing $24 \mathrm{~h}$ after administration.

Sonidegib has multiple pharmacokinetic properties that make it an effective therapeutic agent. ${ }^{47}$ It is highly bound to plasma proteins (over 99\%) in humans. It shows between $69 \%$ and $102 \%$ oral bioavailability when given in solution. Sonidegib also shows high tissue penetration and favorable blood-brain barrier penetration, making it a viable treatment for medulloblastoma. It did not show cytochrome P450 inhibition or induction, minimizing its potential to interact with the metabolism of other drugs. In screens against a panel of receptors, channels, transporters, kinases, and proteases, no activity was identified, limiting its potential for off-target effects. ${ }^{38}$

Sonidegib has a $\mathrm{pH}$-dependent solubility, with a low solubility at high $\mathrm{pH} .{ }^{38,48}$ A Phase I study in Asian patients showed that they have a lower maximum tolerated dose (MTD) due to more severe creatinine kinase (CK) elevation. ${ }^{49}$ Thus, dosing considerations should be taken when treating individuals of East Asian descent as compared to the Western population.

\section{Clinical trials with sonidegib}

Sonidegib was approved for the treatment of aBCC following the demonstration of its efficacy in the Phase II BOLT (BCC outcomes with LDE225 treatment) clinical trials. ${ }^{50}$ Since then, additional clinical trials have been completed to assess the efficacy of sonidegib in aBCC treatment. ${ }^{51}$ The BOLT study included long-term follow-up data of patients treated with sonidegib. This was a multicenter, randomized, double-blind study in which patients took either 200 or $800 \mathrm{mg}$ sonidegib daily. Over $50 \%$ of patients saw objective responses in the $200 \mathrm{mg}$ study arm, whereas the response with the $800 \mathrm{mg}$ study arm was lower. Out of the 94 patients who had laBCC and responded to the drug, 18 progressed or died, while more than half had a response for $>6$ months. More importantly, $80 \%$ of patients with $\mathrm{mBCC}$ showed and maintained an objective response. Long-term follow-up of patients in this study showed that $200 \mathrm{mg}$ sonidegib has a better treatment profile over $800 \mathrm{mg}$, and it maintains extended efficacy in the treatment of aBCC.

Sonidegib efficacy has also been studied to determine the objective response rate, progression-free survival, and time to tumor response. Exposure-safety analysis was performed at doses ranging from 100 to $3,000 \mathrm{mg}$ once daily and 250-750 mg twice daily. Both responders and nonresponders showed similar plasma concentration levels, but there was no correlation between the dosage and probability of tumor response. Similarly, increasing exposure did not show an improvement in progression-free survival nor in time to tumor response. ${ }^{52}$ Thus, patients who fail to respond to lower doses may not benefit from an increase in dose. These results, consistent with other studies, suggest that a $200 \mathrm{mg}$ dose of sonidegib can be used to achieve clinical efficacy and avoid potential adverse events associated with drug toxicity.

Interestingly, the adaptive immune response is promoted in patients with aBCC treated with sonidegib or vismodegib. Immunological markers, including Ber-Ep4, BCL-2, CD4, CD8, and HLA-DR-class II, were measured in aBCC after treatment with vismodegib $(n=22)$ or sonidegib $(n=1)$. Following 4 weeks of treatment, Ber-EP4 and BCL-2 expression in tumors decreased, while HLA expression was upregulated on residual tumor cells, leading to the recruitment of $\mathrm{CD} 8^{+}$cytotoxic $\mathrm{T}$ cells into the tumor mass. Analysis with quantitative polymerase chain reaction revealed that expression of immune response-regulating genes was altered, which is consistent with our previous study that the Hh pathway is responsible for suppressing the immune response, and SMO antagonists relieve the suppression. ${ }^{52,53}$ Although this study was severely 
limited by the low number of patients treated with sonidegib, the result supports the role of Hh signaling for the immune suppressive microenvironment as well as the possibility to combine immune modifiers with Hh signaling inhibition to achieve extended tumor control.

Although sonidegib has been shown to be effective in the treatment of aBCC, its use in patients previously treated with vismodegib will not be effective. The majority of patients who were treated with sonidegib following resistance to vismodegib experienced progressive disease; these patients were found to have SMO mutations that prevented the antagonist effects of SMO antagonists. ${ }^{43}$

One method to detect tumor shrinkage after sonidegib treatment is the use of noninvasive imaging technologies reflectance confocal microscopy and high-definition optical coherence tomography. In patients who showed complete response, pseudocystic structures, or areas of necrosis and fibrosis were observed by these noninvasive techniques. ${ }^{54}$ The treatment effect can be observed without exposing the patients to radiation over multiple occasions. However, residual tumor cells were often found in some cases. Thus, caution should be taken, as always, when using imaging as a tool for guiding treatment. It should be used in concert with other tools to determine the best course of action for the patient.

These studies consistently show sonidegib efficacy in the treatment of aBCC. Sonidegib shows strong promise in the long-term treatment of aBCC, especially when combined with other therapies, including immune modifiers.

There are significant interests in shifting toward the application of sonidegib in the treatment of other cancers renal cell carcinoma, lung cancer, myeloid leukemia, pancreatic cancer, medulloblastoma, ovarian cancer, and lymphoma. Most of the studies, however, were performed in mouse models.

Sonidegib has been shown to be efficacious in the treatment of SCLC. The Hh pathway has been linked to tumor initiation in SCLC. A Phase I study determined the MTD of sonidegib for the treatment of SCLC in combination with etoposide/cisplatin chemotherapy agents. Patients received up to six, 21-day cycles of etoposide/cisplatin with 400 or $800 \mathrm{mg}$ daily sonidegib. A total of $800 \mathrm{mg}$ was determined to be the MTD, with $79 \%$ of patients showing partial response. ${ }^{55}$ Interestingly, a high efficacy is observed when a higher dose of sonidegib is used.

Together, these studies show the potential for sonidegib to treat $\mathrm{BBCC}$ and possibly other cancer types. There is evidence to indicate that sonidegib treatment along with other agents could be more efficacious. While sonidegib is an effective drug, its safety profile must be evaluated for each potential treatment indication.

\section{Safety, tolerability, and adverse effects of sonidegib}

The BOLT study first assessed the safety and tolerability of sonidegib in the treatment of aBCC. ${ }^{50}$ In aBCC treatment with sonidegib, almost all patients experienced at least one adverse event. The most commonly observed adverse events in patients receiving sonidegib (200 or $800 \mathrm{mg}$ ) include (from most common to least common): muscle spasms, alopecia, dysgeusia, nausea, increased CK, fatigue, decreased weight, diarrhea, decreased appetite, myalgia, and vomiting (Table 1). Adverse events leading to dose interruptions, reductions, or treatment discontinuation were less frequent with the $200 \mathrm{mg}$ /day dose in comparison with the $800 \mathrm{mg}$ dose. Grade 1/2 muscle spasms, dysgeusia, nausea, and alopecia were the most common causes of discontinuation. $\mathrm{CK}$ elevation was the most common grade $3 / 4$ event, occurring in $6 \%$ of patients taking the $200 \mathrm{mg}$ dose; women show a lower risk of $\mathrm{CK}$ abnormality than men. ${ }^{52}$ Furthermore, CK elevations were observed at low doses in Japanese patients, which resulted in their lower MTD of sonidegib. ${ }^{48,49}$ Serious adverse events, including rhabdomyolysis and very high $\mathrm{CK}$, were very rarely associated with sonidegib. None of the deaths in the study were associated with sonidegib treatment. ${ }^{50,51}$

Around $70 \%$ of patients taking $200 \mathrm{mg}$ sonidegib were able to stay on treatment for at least 8 months. Despite seeing tumor response, many patients discontinued treatment, citing severe discomfort. However, over half of those who discontinued experienced only grade $1 / 2$ adverse events. Many of these patients did not feel the need to suffer through treatment after already seeing benefits. ${ }^{53}$ Management strategies for adverse events combined with improved patient education regarding treatment plans may lead to increased patient acceptance and tolerance of sonidegib therapy.

Adverse events associated with treatment are linked to the inhibition of the Hh pathway in normal tissues. Although adverse events may be mild, the long-term experience can cause patients to experience decreased quality of life, treatment interruption, and discontinuation before achieving any therapeutic benefit. These adverse events may have a significant impact on the clinical outcome of the patient. Improved knowledge of the mechanisms and management of adverse events will help physicians to better guide their treatments with appropriate prevention or intervention. 
Table I Summary of smoothened antagonists

\begin{tabular}{|c|c|c|c|c|c|c|c|c|}
\hline Name & LDE225 & GDC0499 & IPI-926 & PF-044499I3 & TAK-44I & $\begin{array}{l}\text { BMS833923/ } \\
\text { XL-139 }\end{array}$ & LY-2940680 & LEQ506 \\
\hline Drug name & $\begin{array}{l}\text { Sonidegib/ } \\
\text { Odomzo }\end{array}$ & $\begin{array}{l}\text { Vismodegib/ } \\
\text { Erivedge }\end{array}$ & Saridegib & Glasdegib & & & Taladegib & \\
\hline CAS number & $956697-53-3$ & $879085-55-9$ & $1037210-93-7$ & $1095173-27-5$ & || $8623 \mid-83-3$ & $1059734-66-5$ & $|25886|-20-9$ & $1204975-42-7$ \\
\hline MW & 485.5 & 421.3 & 504.3 & 374.4 & 576.2 & 473.2 & 512.5 & 432.56 \\
\hline NCT number & $\begin{array}{l}\text { NCT02 I I I I 87; } \\
\text { NCT02 I } 95973 ; \\
\text { NCT020865I3; } \\
\text { NCT02 I } 5 \text { I864; } \\
\text { NCT02 I 38929; } \\
\text { NCT02086552; } \\
\text { NCT02358I6I; } \\
\text { NCT02 I 29I0I }\end{array}$ & $\begin{array}{l}\text { NCT02639III7; } \\
\text { NCT023375I } 7 \text {; } \\
\text { NCT0I835626; } \\
\text { NCT02956889; } \\
\text { NCT02694224; } \\
\text { NCT0I60II I84; } \\
\text { NCT02648048; } \\
\text { NCT02690948; } \\
\text { NCT02593760; } \\
\text { NCT02436408; } \\
\text { NCT0278I 389; } \\
\text { NCT0209II4I; } \\
\text { NCT02073838; } \\
\text { NCT025230I4; } \\
\text { NCT0I8786I7; } \\
\text { NCT02465060; } \\
\text { NCT02693535; } \\
\text { NCT0278820I }\end{array}$ & NCTOI 383538 & $\begin{array}{l}\text { NCT0I84I333; } \\
\text { NCT02367456; } \\
\text { NCT02038777; } \\
\text { NCT0I546038; } \\
\text { NCT02226I } 72\end{array}$ & 1204073 & NCT0I 218477 & $\begin{array}{l}\text { NCT02784795; } \\
\text { NCT02530437 }\end{array}$ & NCTII 06508 \\
\hline $\begin{array}{l}\text { Recommended } \\
\text { dose }\end{array}$ & $400 \mathrm{mg}$ qd & $150 \mathrm{mg}$ qd & $160 \mathrm{mg} q \mathrm{~d}$ & $100 \mathrm{mg} q \mathrm{~d}$ & $\begin{array}{l}\text { MTD } \\
\mathrm{I}, 600 \mathrm{mg} \text { qd }\end{array}$ & 100 mg qd & $200 \mathrm{mg}$ qd & $250 \mathrm{mg}$ bid \\
\hline Binding to SMO & $\begin{array}{l}\text { Drug-binding } \\
\text { pocket }\end{array}$ & $\begin{array}{l}\text { Drug-binding } \\
\text { pocket }\end{array}$ & $\begin{array}{l}\text { Drug-binding } \\
\text { pocket }\end{array}$ & $\begin{array}{l}\text { Drug-binding } \\
\text { pocket }\end{array}$ & $\begin{array}{l}\text { Not } \\
\text { determined } \\
\text { (possibly not } \\
\text { in the pocket) }\end{array}$ & Not known & $\begin{array}{l}\text { Drug-binding } \\
\text { pocket }\end{array}$ & $\begin{array}{l}\text { Not known } \\
\text { (possibly } \\
\text { not in the } \\
\text { pocket) }\end{array}$ \\
\hline Adverse events & $\begin{array}{l}\text { Muscle spasms; } \\
\text { alopecia; } \\
\text { dysgeusia; } \\
\text { nausea; } \\
\text { creatine kinase } \\
\text { elevation; } \\
\text { vomiting/ } \\
\text { weight loss/ } \\
\text { diarrhea }\end{array}$ & $\begin{array}{l}\text { Muscle spasms; } \\
\text { weight loss; } \\
\text { alopecia; } \\
\text { fatigue; low } \\
\text { appetite; } \\
\text { diarrhea }\end{array}$ & $\begin{array}{l}\text { Liver function } \\
\text { abnormality; } \\
\text { fatigue; muscle } \\
\text { spasms; } \\
\text { vomiting/ } \\
\text { nausea; rash; } \\
\text { diarrhea }\end{array}$ & $\begin{array}{l}\text { Dysgeusia; } \\
\text { fatigue; low } \\
\text { appetite; } \\
\text { dizziness; } \\
\text { dehydration; } \\
\text { diarrhea }\end{array}$ & $\begin{array}{l}\text { Hyponatremia; } \\
\text { fatigue; } \\
\text { dysgeusia; } \\
\text { alopecia; } \\
\text { muscle spasms }\end{array}$ & 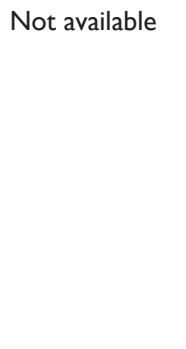 & Not available & Not available \\
\hline $\begin{array}{l}\text { Single agent }(\mathrm{S}) \text { or } \\
\text { combined therapy }(\mathrm{C})\end{array}$ & S, C & $\mathrm{S}, \mathrm{C}$ & C & $\mathrm{S}, \mathrm{C}$ & $S$ & $S$ & $\mathrm{~S}, \mathrm{C}$ & $\mathrm{S}$ \\
\hline
\end{tabular}

Abbreviations: MTD, maximum tolerated dose; SMO, smoothened; CAS, Chemical Abstracts Service; MW, molecular weight; NCT, National Clinical Trial; bid, twice daily; qd, once daily.

Muscle spasms can be relieved by passive stretching, heating, cryotherapy, exercise, electrical stimulation, splinting, and changing sitting or sleeping positions. Pharmacologic treatments include calcium channel blockers, nerve stabilizers, or magnesium supplements. A number of other pharmaceuticals have been recommended, especially for cases in which muscle spasms spread to the abdomen. Almost $40 \%$ of patients taking $200 \mathrm{mg}$ sonidegib experience dysgeusia, often leading to weight loss. Delta-9-tetrahydrocannabinol showed promise in improving taste sensation and appetite. Consulting with a dietician can be beneficial for these patients and has been shown to decrease the onset of dysgeusia. Hair loss (alopecia) in these patients can affect their psychosocial well-being, leading to problems such as depression.

Sonidegib and other Hh signaling inhibitors block follicles from starting the anagen growth phase after shedding of hair in telogen, leading to extended, or in some cases, permanent hair loss. Minoxidil and dihydrotestosterone inhibitors may help promote hair growth. Weight loss can be associated with the disease process or the treatment itself. It usually begins at least 6 months following the beginning of treatment. Again, dieticians and supplementation can be helpful in these cases. 
Fatigue is often a result of the culmination of other adverse events, including the muscle spasms and decreased appetite. Pharmacologic interventions may help, but physical activity, psychosocial intervention, sleep therapy, and nutritional supplementation may also help. Nausea is one of the earliest reported adverse events. Sonidegib was reported to be a moderate to high emetogenic agent. Serotonin inhibitors, antipsychotics, and other pharmaceutical agents can be provided for their antiemetic effects. In addition to regular monitoring of CK levels before and during treatment, health care providers should watch for symptoms of rhabdomyolysis, including muscle pain, tenderness, and weakness. ${ }^{56}$ Despite the multitude of adverse events patients may experience, application of these strategies can improve patient tolerance of treatment.

In the treatment of SCLC with sonidegib, the adverse events are markedly different from those seen in aBCC. This may be the result of a higher recommended dose of sonidegib used to treat SCLC (800 mg) versus aBCC (200 mg). SCLC patients often experience grade $3 / 4$ toxicities including anemia, neutropenia, CK elevation, fatigue, and nausea. The toxicity of sonidegib led to discontinuation of treatment in one patient. ${ }^{55}$

The safety profile of sonidegib in cancers besides aBCC has not been thoroughly studied as of yet. As more of these studies move toward human trials, we can expect to see further evaluation of safety and tolerability, which will likely vary among different cancer types. However, the safety studies done in aBCC patients illustrate that although the drug is effective, it does have significant related adverse events. Many patients discontinue due to the long-term grade $1 / 2$ events they experience, indicating lower patient quality of life, acceptability, and adherence. Nevertheless, the benefit of the drug is much greater than the potential side effects, and through patient education and management strategies, adverse events can be minimized and treatment can be continued further to improve the outcomes.

\section{Other SMO inhibitors}

Vismodegib is a first-in-class HPI that was approved by the FDA in 2012 for the treatment of aBCC, and it is currently being studied for use in other cancers, including colorectal cancer, pancreatic cancer, and medulloblastoma. Vismodegib acts in the same drug-binding pocket as sonidegib. In its Phase I study, about half of the patients treated with vismodegib showed tumor response. Patients in the Phase II study showed lower tumor response and many experienced serious adverse events. ${ }^{37}$ However, over $50 \%$ of patients experience refractory $\mathrm{aBCC}$ and a portion of initial responders develop resistance. In these patients, resistance to sonidegib is also predicted. ${ }^{43}$ Adverse events associated with vismodegib treatment include grade 3 fatigue, hyponatremia, muscle spasms, and atrial fibrillation. Although vismodegib is fairly efficacious and has a similar safety profile to that of sonidegib, it seems to have more severe adverse events.

Cyclopamine was among the first SMO antagonists to be developed. It functions as an inverse agonist of SMO. However, it exhibits poor oral solubility and has many offtarget adverse effects, making it a poor candidate for use in human cancer treatment. IPI-262, BMS-833923, Taladegib, PF-04449913, TAK-441, and LEQ506 are being investigated in clinical trials for treatment of aBCC. ${ }^{37}$ In a study comparing the pharmacologic properties of these drugs, there was a significant variation in their inhibiting potencies as well as their ability to be used in a topical application. For example, LEQ-506 and TAK-441 are favorable in the treatment of minimally invasive $\mathrm{BCC}$ due to their properties in a topical formulation and their low side effects. In contrast, sonidegib and vismodegib have stronger side effects, limiting their use in less invasive BCCs. ${ }^{57}$ The development of these SMO inhibitors promises the coming of therapies that will offer diverse properties in terms of treatment indications, clinical efficacy, and safety profiles. ${ }^{58-60}$

\section{Perspectives}

The evaluation of sonidegib's clinical efficacy and its safety profile indicate its promise for treatment of aBCC and possibly for other cancer types. A large proportion of patients see clinical benefits with only mild to moderate adverse events. Despite the rare serious adverse events, the complete response rate $(-30 \%)$ is fairly low for a tumor type driven mostly by mutations in the PTCH1 gene. The response rate for $\mathrm{mBCC}$ is even worse $(<5 \%)$. There are a number of reasons for the different responses from $\mathrm{BCC}$ patients. First, the genetic mutations underlying the $\mathrm{Hh}$ signaling activation in the BCCs were not known at the time of clinical trials. For gene mutations in SMO or SUFU, which may contribute to $\sim 20 \%$ of tumors, sonidegib and vismodegib will not be effective. Second, the response of patients to drugs varies significantly; detailed analysis of the biomarkers following the treatment may reveal additional mechanisms as to why some patients respond better than others. Third, while Hh signaling is the single most important pathway for BCC development, other signaling pathways do play important roles, such as p53 gene mutations. Fourth, drug resistance occurs frequently following treatment with SMO antagonists such as vismodegib. 
The resistance may be from mutations of SMO itself or other important players such as PI3K signaling.

Thus, there is still a lot of work needed for better treatment of BCCs using SMO inhibitors. Patient education and management strategies can significantly improve a patient's way of life during treatment. When developing treatment plans, an important consideration is the propensity of patients to develop resistance. While a large proportion of patients show resistance, evaluating tumor response regularly will allow a physician to determine whether sonidegib is the appropriate treatment. Furthermore, genotyping patient tumors could identify patients with mutations leading to resistant tumors and help to avoid unnecessary treatment with a SMO inhibitor.

Sonidegib may have a strong role as an adjunct therapy in the treatment of other cancers. With its observed potentiating effects in multiple cancer types, the approval of additional clinical applications for sonidegib can be anticipated. Nevertheless, although sonidegib is a potent HPI, it will not be effective in suppressing noncanonical Hh signaling since these signaling events bypass SMO-dependent signaling (Figure 1). Growing evidence suggests that certain cancer types, including pancreatic cancer, may exhibit aberrant noncanonical pathway activation. Thus, we may see benefit from the development of a common downstream Hh signaling molecule antagonist, such as inhibitors for the Gli transcription factors.

\section{Acknowledgments}

Current research in the laboratory of $\mathrm{J}$ Xie is supported by grants from the National Cancer Institute CA155086, Riley Children's Foundation, Jeff Gordon Children's Research Foundation, and Wells Center for Pediatric Research. The authors take this opportunity to thank all the investigators in this field for their works.

\section{Disclosure}

The authors report no other conflicts of interest in this work.

\section{References}

1. Nusslein-Volhard C, Wieschaus E. Mutations affecting segment number and polarity in drosophila. Nature. 1980;287(5785):795-801.

2. Krauss S, Concordet JP, Ingham PW. A functionally conserved homolog of the drosophila segment polarity gene hh is expressed in tissues with polarizing activity in zebrafish embryos. Cell. 1993;75(7):1431-1444.

3. Echelard Y, Epstein DJ, St-Jacques B, et al. Sonic hedgehog, a member of a family of putative signaling molecules, is implicated in the regulation of CNS polarity. Cell. 1993;75(7):1417-1430.

4. Riddle RD, Johnson RL, Laufer E, Tabin C. Sonic hedgehog mediates the polarizing activity of the ZPA. Cell. 1993;75(7):1401-1416.

5. Chang DT, Lopez A, von Kessler DP, et al. Products, genetic linkage and limb patterning activity of a murine hedgehog gene. Development. 1994;120(11):3339-3353.
6. Roelink H, Augsburger A, Heemskerk J, et al. Floor plate and motor neuron induction by vhh-1, a vertebrate homolog of hedgehog expressed by the notochord. Cell. 1994;76(4):761-775.

7. Jiang J, Hui CC. Hedgehog signaling in development and cancer. Dev Cell. 2008;15(6):801-812.

8. Yang L, Xie G, Fan Q, Xie J. Activation of the hedgehog-signaling pathway in human cancer and the clinical implications. Oncogene. 2010;29(4): 469-481.

9. Varjosalo M, Taipale J. Hedgehog: functions and mechanisms. Genes Dev. 2008;22(18):2454-2472.

10. Corbit KC, Aanstad P, Singla V, Norman AR, Stainier DY, Reiter JF. Vertebrate smoothened functions at the primary cilium. Nature. 2005; 437(7061):1018-1021.

11. Huangfu D, Liu A, Rakeman AS, Murcia NS, Niswander L, Anderson KV. Hedgehog signalling in the mouse requires intraflagellar transport proteins. Nature. 2003;426(6962):83-87.

12. Rohatgi R, Milenkovic L, Scott MP. Patched1 regulates hedgehog signaling at the primary cilium. Science. 2007;317(5836):372-376.

13. Allen BL, Song JY, Izzi L, et al. Overlapping roles and collective requirement for the coreceptors GAS1, CDO, and BOC in SHH pathway function. Dev Cell. 2011;20(6):775-787.

14. Izzi L, Levesque M, Morin S, et al. Boc and Gas1 each form distinct Shh receptor complexes with Ptch1 and are required for Shh-mediated cell proliferation. Dev Cell. 2011;20(6):788-801.

15. Yao S, Lum L, Beachy P. The ihog cell-surface proteins bind hedgehog and mediate pathway activation. Cell. 2006;125(2):343-357.

16. Linder B, Weber S, Dittmann K, Adamski J, Hahn H, Uhmann A. A Functional and putative physiological role of calcitriol in patched $1 /$ smoothened interaction. The J Biol Chem. 2015;290(32):19614-19628.

17. Zhou Z, Yao X, Li S, et al. Deubiquitination of Ci/Gli by Usp7/HAUSP regulates hedgehog signaling. Dev Cell. 2015;34(1):58-72.

18. Cohen M, Kicheva A, Ribeiro A, et al. Ptch1 and Gli regulate Shh signalling dynamics via multiple mechanisms. Nat Commun. 2015;6:6709.

19. Canettieri G, Di Marcotullio L, Coni S, Greco A, Gulino A. Turning off the switch in medulloblastoma: the inhibitory acetylation of an oncogene. Cell Cycle. 2010;9(11):2047-2048.

20. Chi S, Xie G, Liu H, et al. Rab23 negatively regulates Gli1 transcriptional factor in a $\mathrm{Su}(\mathrm{Fu})$-dependent manner. Cell Signal. 2012; 24(6):1222-1228

21. Johnson RL, Rothman AL, Xie J, et al. Human homolog of patched, a candidate gene for the basal cell nevus syndrome. Science. 1996;272(5268): 1668-1671.

22. Hahn H, Wicking C, Zaphiropoulous PG, et al. Mutations of the human homolog of drosophila patched in the nevoid basal cell carcinoma syndrome. Cell. 1996;85(6):841-851.

23. Wang DH, Clemons NJ, Miyashita T, et al. Aberrant epithelialmesenchymal hedgehog signaling characterizes barrett's metaplasia. Gastroenterology. 2010;138(5):1810-1822

24. Gu D, Liu H, Su GH, et al. Combining hedgehog signaling inhibition with focal irradiation on reduction of pancreatic cancer metastasis. Mol Cancer Ther. 2013;12(6):1038-1048.

25. Faiao-Flores F, Alves-Fernandes DK, Pennacchi PC, et al. Targeting the hedgehog transcription factors GLI1 and GLI2 restores sensitivity to vemurafenib-resistant human melanoma cells. Oncogene. 2016. [Epub ahead of print].

26. Schreck KC, Taylor P, Marchionni L, et al. The Notch target Hes1 directly modulates Gli1 expression and Hedgehog signaling: a potential mechanism of therapeutic resistance. Cli Cancer Res. 2010;16(24): 6060-6070

27. Domingo-Domenech J, Vidal SJ, Rodriguez-Bravo V, et al. Suppression of acquired docetaxel resistance in prostate cancer through depletion of notch-and hedgehog-dependent tumor-initiating cells. Cancer Cell. 2012;22(3):373-388

28. Keysar SB, Le PN, Anderson RT, et al. Hedgehog signaling alters reliance on EGF receptor signaling and mediates anti-EGFR therapeutic resistance in head and neck cancer. Cancer Res. 2013;73(11): 3381-3392. 
29. Liu $\mathrm{Z}, \mathrm{Xu}$ J, He J, et al. A critical role of autocrine sonic hedgehog signaling in human CD138+ myeloma cell survival and drug resistance. Blood. 2014;124(13):2061-2071.

30. Zahreddine HA, Culjkovic-Kraljacic B, Assouline S, et al. The sonic hedgehog factor GLI1 imparts drug resistance through inducible glucuronidation. Nature. 2014;511(7507):90-93.

31. Della Corte CM, Bellevicine C, Vicidomini G, et al. SMO Gene Amplification and activation of the hedgehog pathway as novel mechanisms of resistance to anti-epidermal growth factor receptor drugs in human lung cancer. Clin Cancer Res. 2015;21(20):4686-4697.

32. Alonso S, Hernandez D, Chang YT, et al. Hedgehog and retinoid signaling alters multiple myeloma microenvironment and generates bortezomib resistance. J Clin Invest. 2016;126(12):4460-4468.

33. Lin EH, Kao YR, Lin CA, et al. Hedgehog pathway maintains cell survival under stress conditions, and drives drug resistance in lung adenocarcinoma. Oncotarget. 2016;7(17):24179-24193.

34. Mudigonda T, Pearce DJ, Yentzer BA, Williford P, Feldman SR. The economic impact of non-melanoma skin cancer: a review. J Natl Compr Canc Netw. 2010;8(8):888-896.

35. Rubin LL, de Sauvage FJ. Targeting the hedgehog pathway in cancer. Nat Rev Drug Discov. 2006;5(12):1026-1033.

36. Low JA, de Sauvage FJ. Clinical experience with hedgehog pathway inhibitors. J Clin Oncol. 2010;28(36):5321-5326.

37. Basset-Seguin N, Sharpe HJ, de Sauvage FJ. Efficacy of hedgehog pathway inhibitors in basal cell carcinoma. Mol Cancer Ther. 2015;14(3): 633-641.

38. Pan S, Wu X, Jiang J, et al. Discovery of NVP-LDE225, a potent and selective smoothened antagonist. ACS Med Chem Lett. 2010;1(3) $130-134$.

39. Sharpe HJ, Wang W, Hannoush RN, de Sauvage FJ. Regulation of the oncoprotein smoothened by small molecules. Nat Chem Biol. 2015;11(4): 246-255

40. Wang C, Wu H, Evron T, et al. Structural basis for smoothened receptor modulation and chemoresistance to anticancer drugs. Nat Commun 2014;5:4355

41. Nachtergaele S, Whalen DM, Mydock LK, et al. Structure and function of the smoothened extracellular domain in vertebrate hedgehog signaling. Elife. 2013;2:e01340.

42. Wang C, Wu H, Katritch V, et al. Structure of the human smoothened receptor bound to an antitumour agent. Nature. 2013;497(7449):338-343.

43. Danial C, Sarin KY, Oro AE, Chang AL. An investigator-initiated open-label trial of sonidegib in advanced basal cell carcinoma patients resistant to vismodegib. Clin Cancer Res. 2016;22(6):1325-1329.

44. Zollinger M, Lozac'h F, Hurh E, Emotte C, Bauly H, Swart P. Absorption, distribution, metabolism, and excretion (ADME) of (1) (4) C-sonidegib (LDE225) in healthy volunteers. Cancer Chemother Pharmacol. 2014;74(1):63-75.

45. Sharma MR, Karrison TG, Kell B, et al. Evaluation of food effect on pharmacokinetics of vismodegib in advanced solid tumor patients. Clin Cancer Res. 2013;19(11):3059-3067.

46. Graham RA, Lum BL, Cheeti S, et al. Pharmacokinetics of hedgehog pathway inhibitor vismodegib (GDC-0449) in patients with locally advanced or metastatic solid tumors: the role of alpha-1-acid glycoprotein binding. Clin Cancer Res. 2011;17(8):2512-2520.
47. Goel V, Hurh E, Stein A, et al. Population pharmacokinetics of sonidegib (LDE225), an oral inhibitor of hedgehog pathway signaling, in healthy subjects and in patients with advanced solid tumors. Cancer Chemother Pharmacol. 2016;77(4):745-755.

48. Zhou J, Quinlan M, Glenn K, et al. Effect of esomeprazole, a proton pump inhibitor on the pharmacokinetics of sonidegib in healthy volunteers. Br J Clin Pharmacol. 2016;82(4):1022-1029.

49. Minami H, Ando Y, Ma BB, et al. Phase I, multicenter, open-label, dose-escalation study of sonidegib in Asian patients with advanced solid tumors. Cancer Sci. 2016;107(10):1477-1483.

50. Dummer R, Guminski A, Gutzmer R, et al. The 12-month analysis from basal cell carcinoma outcomes with LDE225 treatment (BOLT): a phase II, randomized, double-blind study of sonidegib in patients with advanced basal cell carcinoma. J Am Acad Dermatol. 2016; 75(1):113-125.e115.

51. Migden MR, Guminski A, Gutzmer R, et al. Treatment with two different doses of sonidegib in patients with locally advanced or metastatic basal cell carcinoma (BOLT): a multicentre, randomised, double-blind phase 2 trial. Lancet Oncol. 2015;16(6):716-728.

52. Zhou J, Quinlan M, Hurh E, Sellami D. Exposure-response analysis of sonidegib (LDE225), an oral inhibitor of the hedgehog signaling pathway, for effectiveness and safety in patients with advanced solid tumors. J Clin Pharmacol. 2016;56(11):1406-1415.

53. Fan Q, Gu D, Liu H, et al. Defective TGF-beta signaling in bone marrow-derived cells prevents hedgehog-induced skin tumors. Cancer Res. 2014;74(2):471-483.

54. Maier T, Kulichova D, Ruzicka T, Berking C. Noninvasive monitoring of basal cell carcinomas treated with systemic hedgehog inhibitors: pseudocysts as a sign of tumor regression. J Am Acad Dermatol. 2014;71(4):725-730.

55. Pietanza MC, Litvak AM, Varghese AM, et al. A phase I trial of the hedgehog inhibitor, sonidegib (LDE225), in combination with etoposide and cisplatin for the initial treatment of extensive stage small cell lung cancer. Lung Cancer. 2016;99:23-30.

56. Lacouture ME, Dreno B, Ascierto PA, et al. Characterization and management of hedgehog pathway inhibitor-related adverse events in patients with advanced basal cell carcinoma. Oncologist. 2016; 21(10):1218-1229.

57. Lauressergues E, Heusler P, Lestienne F, et al. Pharmacological evaluation of a series of smoothened antagonists in signaling pathways and after topical application in a depilated mouse model. Pharmacol Res Perspect. 2016;4(2):e00214.

58. Sekulic A, Migden MR, Oro AE, et al. Efficacy and safety of vismodegib in advanced basal-cell carcinoma. $N$ Eng J Med. 2012;366(23) 2171-2179.

59. Lyons TG, O’Kane GM, Kelly CM. Efficacy and safety of vismodegib: a new therapeutic agent in the treatment of basal cell carcinoma. Expert Opin Drug Saf. 2014;13(8):1125-1132.

60. Sofen H, Gross KG, Goldberg LH, et al. A phase II, multicenter, open-label, 3-cohort trial evaluating the efficacy and safety of vismodegib in operable basal cell carcinoma. J Am Acad Dermatol. 2015;73(1) 99-105.e101.
OncoTargets and Therapy

\section{Publish your work in this journal}

OncoTargets and Therapy is an international, peer-reviewed, open access journal focusing on the pathological basis of all cancers, potential targets for therapy and treatment protocols employed to improve the management of cancer patients. The journal also focuses on the impact of management programs and new therapeutic agents and protocols on

\section{Dovepress}

patient perspectives such as quality of life, adherence and satisfaction. The manuscript management system is completely online and includes a very quick and fair peer-review system, which is all easy to use. Visit http://www.dovepress.com/testimonials.php to read real quotes from published authors. 